\title{
ANALysis OF THE CURRENT APPLICATION OF AR IN THE CONTEXT OF TPM IN SLOVAKIA ORGANIZATIONS
}

\author{
Lucia Grajzova, Samuel Janik, Milos Cambal \& Miroslava Mlkva
}
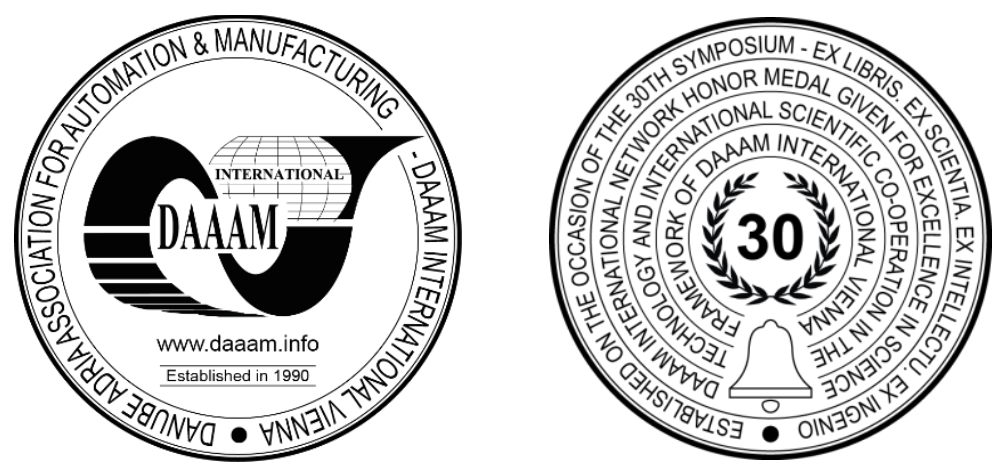

This Publication has to be referred as: Grajzova, L[ucia]; Janik, S[amuel] \& Mlkva, M[iroslava] (2021). Analysis of the Current Application of AR in the Context of TPM in Slovakia Organizations, Proceedings of the 32nd DAAAM International Symposium, pp.0546-0554, B. Katalinic (Ed.), Published by DAAAM International, ISBN 978-3-90273433-4, ISSN 1726-9679, Vienna, Austria

DOI: $10.2507 / 32$ nd.daaam.proceedings.079

\begin{abstract}
Industrial production has undergone significant changes in the last decade. Competition has increased dramatically, and customers are focusing on product quality, delivery time and product costs. For this reason, companies should focus not only on the continuous improvement of their products, but also on their processes. Total Productive Maintenance (TPM) is a methodology aimed at increasing the efficiency and longevity of equipment and machinery. Augmented reality is a direct or indirect view of the physically real environment, parts of which are enriched in digital, mostly textual, or pictorial form with additional information relevant to the object one is looking at. The aim of the paper was to analyse and describe the current situation of implementation of AR technology in industrial enterprises of Slovakia as a means to improve and explore opportunities for the future adaption of the TPM philosophy in the Industry 4.0 environment.
\end{abstract}

Keywords: augmented reality; digital technologies; Industry 4.0; total productive management; 5S;

\section{Introduction}

The Fourth Industrial Revolution is a topic that is currently being fully discussed in all areas. We can simply say that this is a consistent introduction of digital technologies into production. Digital technologies have developed rapidly in recent years and their use is becoming a major challenge for businesses. An industrial society that wants to succeed in the modern world must never afford to neglect the use of modern technology in production processes. The efficiency with which it is able to bring a new product to market also often reflects the profitability of companies with a competitive advantage and, ultimately, may also determine the company's future survival in the market.

A manufacturing organization should be able to provide its customers with quality products. In order to stay active in today's market, these organizations must guarantee that their processes are being monitored and constantly improved. More efficient quality systems are required when the production volumes are increased, there are a number of techniques for controlling product and process quality like Failure Mode and Effect Analysis (FMEA), Statistical Process Control (SPC), Design of Experiments (DoE) and Total Productive Maintenance (TPM) [1]. In this article, the authors focused on identifying the extent of AR application in industrial enterprises in Slovakia. The research was carried out using the questionnaire method and 230 answers were obtained from medium and large companies. 
The purpose of this paper is to analyse the extent and manner of application of AR in the maintenance processes and to identify future assumptions of its use.

In the next part of the article, we will try to find answers to the following questions.

1. Is there a presumption that Slovak companies will be able to innovate their processes by using new technologies offered by the Fourth Industrial Revolution?

2. Do our respondents see potential in the use of AR?

3. Is there still room for investment in AR in order to make it more efficient given the current state of its application?

4. Do our organizations have the ability to adapt in the implementation of other future possibilities that could AR offer in relation to the global market predictions with the goal to stay competitive in the ever-changing environment?

\subsection{Total productive maintenance}

The origin of TPM can be traced back to 1951 when preventive maintenance was introduced in Japan. However, the concept of preventive maintenance was taken from the USA. Nippondenso was the first company which introduced plantwide preventive maintenance in 1960 [2]. Total productive maintenance is maintenance activities that are productive and implemented by all employees. TPM involves everyone in the organization from assembly line workers to senior management in equipment improvement. It encompasses all departments including: Maintenance, Operations, Facilities, Design Engineering, Project Engineering, Construction Engineering, Inventory and Stores, Purchasing, Accounting and Finance, Plant and Site Management [3].

Total Productive Maintenance is an extremely comprehensive approach to operational efficiency and maintenance included. It is one of the basic blocks used in lean manufacturing, after all it is not possible to improve processes if we cannot rely on equipment and machines. TPM is a maintenance management system that includes the care of fixed assets and considers the impact of maintenance on productivity, quality, safety and all matters that affect the employees in the company. TPM represents the Japanese approach to maximizing the efficiency of machines and equipment and thus creating optimal conditions in the relationship "Human - Machine - Environment" [4].

\section{TPM goals}

TPM has the following five goals [3]:

1. Improving equipment effectiveness.

2. Improving maintenance efficiency and effectiveness.

3. Early equipment management and maintenance prevention.

4. Training to improve the skills of all people involved.

5. Involving operators in routine maintenance.

\section{TPM Built on 5S}

TPM has as its foundation in another management methodology, also originating from Japan, known as 5S. This is an organizational strategy, based around the Japanese concepts of seiri, seiton, seisō, seiketsu, and shitsuke. Translated, these words mean "Sort," "Set in order," "Shine," "Standardize," and "Sustain." 5S is focused on organizing the workplace environment to improve efficiency and effectiveness. This methodology establishes rules and creates a mindset of efficiency and order. As such, it helps connect the individual worker to his space and tools in a productive and efficient way and lays the groundwork for a system like TPM to be as effective as possible [5].

\section{TPM pillars}

The key areas of TPM are addressed by eight different activities, popularly termed as eight pillars of TPM. The Eightpillar methodology of TPM results in rising labour productivity via contraction in maintenance costs and production stoppages and thereby having cut back on downtimes [6].

The eight TPM pillars include:

1. Autonomous Maintenance,

2. Focused Maintenance,

3. Planned Maintenance,

4. Quality Maintenance,

5. Early Equipment Management,

6. Education and Training,

7. Safety, Health \& Environmnet,

8. Office TPM [7]. 
Total Productive Maintenance

\begin{tabular}{|c|c|}
\hline \multicolumn{2}{|c|}{ Fewer Defects and Less Downtime $=$ Increased Efficiency } \\
\hline Autonomous Maintenance & Planned Maintenance \\
\hline Quality Maintenance & Focused Improvement \\
\hline Early Equipment Management & Training \& Education \\
\hline Safety, Health, \& Environment & TPM in Administration \\
\hline \multicolumn{2}{|c|}{ 5S Practices } \\
\hline
\end{tabular}

Fig. 1. Pillars of TPM [8]

The pillars shown in Figure 1 represent a house consisting of eight columns, with a logical sequence. It is necessary to build the pillars before it is possible to build a "house". The definition of the pillars depends on the philosophy and internal structure of the organization and should be adapted to the existing culture and approach of the organization [9].

1. Autonomous Maintenance - this pillar aims at developing operator ownership. The operator performs day-to-day tasks to be able to develop skills and in turn mastery of the equipment, thereby freeing up the skilled maintenance people. This way they can spend more time on technical repairs and other value-added activities. In this activity, operators are responsible for safeguarding their equipment to avoid operating abnormalities [10].

2. Focused Maintenance - Recurring problems are identified and resolved by cross-functional teams. Combines the collective talents of a company to create an engine for continuous improvement.

3. Planned Maintenance - Maintenance pre-empts malfunction while interventions by high-level technicians are carefully planned so that minimal downtime is required for any software updates or part replacements. Planned Maintenance follows the concept of zero failures similar to Focused Improvement. Zero failures mean zero defects, zero reworks and zero accidents [5] [10].

4. Quality Maintenance - It is aimed towards customer delight through the highest quality through defect-free manufacturing. Focus is on eliminating non-conformances in a systematic manner, much like a focused improvement. QM activities are to set equipment conditions that preclude quality defects, based on the basic concept of maintaining perfect equipment to maintain perfect quality of products. The condition is checked and measure in time series to very that measure values are within standard values to prevent defects [11].

5. Early Equipment Management - is also occasionally referred to as TPM for Design to highlight the fact that it is about the early involvement of existing operators and maintainers at the very start of a capital equipment investment, namely at the concept and definition stage [12].

6. Education and Training - Continuous improvement includes operator and work area education and training which improves morale, retention, and efficiency.

7. Safety, Health and Environment Control - Facility-wide safety is prioritized which positively impacts the sustained success of the TPM program.

8. Office TPM - the TPM office should be formed after activating the previous pillars. Office or, in other words, the office should be formed to monitor the improvement of productivity, efficiency in administrative work to eliminate losses, which involves analysing processes and procedures [13].

The 8 pillars remain the fundamentals of the industry. But under a large modernization movement called Industry 4.0 and on which we can argue the revolutionary nature, one can ask a simple question:

\section{"How is this revolution going provide forever more efficient maintenance? “}

The answer to this question is in Industry 4.0, Big Data or the Internet of Things, artificial intelligence, cyber-physical system, or even augmented reality appear as a digital upgrade and as many potential levers for improvement.

\section{Industry 4.0}

Industry 4.0 is currently one of the most popular topics in the world, both in industry and in academia. The Fourth Industrial Revolution plays an important role in defining new organizational strategies and seizing the opportunities of digitization at all levels of production and services. Its implementation is a combination of several physical and digital technologies, such as artificial intelligence, cloud computing, additive manufacturing, adaptive robotics, the Internet of Things (IoT), and augmented reality. The main goal of the implementation of industry 4.0 technologies is industrial transformation, increasing efficiency and productivity to achieve greater competitiveness of organizations) [15]. Industry 4.0 is a revolution in manufacturing that offers new opportunities based on the integration of Industry 4.0 technologies with manufacturing and its parts, which can lead to improved performance with minimal resources [16]. 
Like the lean manufacturing paradigm, the thinking paradigm in the context of Industry 4.0 offers promising solutions to the future challenges facing organizations. The only question remains whether and how these two philosophies can merge [17].

\section{Augmented reality}

Masood [18] speaks of the augmented reality as a key technology of the fourth industrial revolution. AR supports the implementation and development of the concepts of the fourth industrial revolution. By using AR technology, employees can overcome barriers between the physical and increasingly important digital worlds [20]. To define the operation of AR devices more specifically, Azuma [20] talks about the need to combine real and virtual objects in a real environment and time. Both real and virtual objects must be geometrically aligned in the real world. The basic idea of AR is to effectively provide the necessary information to the user virtually without restricting him at work [14]. Current developments in technology and industry are dynamic and complex, leading to a highly competitive and dynamic business environment. The manufacturing industry faces new challenges that require a holistic view of the four major classes of manufacturing attributes, i. j. cost, time, quality, and flexibility. The challenge is to implement integrated AR-supported simulation tools that could improve manufacturing operations as well as product and process development [19].

AR technology is used in a wide range of industries such as marketing, logistics, manufacturing, and maintenance. Studies that focus on identifying Industry 4.0 and maintenance relationships show positive results that support their synergy. Maintenance staff using AR can work more efficiently in performing technical maintenance tasks, and AR can also serve as support in maintenance decision-making processes [20] [15]. Complex tasks that are associated with maintenance in industrial enterprises are suitable candidates for the implementation of augmented reality. Flexible training options and access to real-time documentation meet the requirements for the appropriate application of AR technology by maintenance technicians [14].

The first attempts to implement AR into maintenance processes date back to the early 1990s. In 2013, Volkswagen introduced a tablet, smartphone application called MARTA (Mobile Augmented Reality Technical Assistance), which provided technicians with detailed instructions on car repair and maintenance [21]. At present, repair and maintenance technicians are beginning to use AR headsets and glasses in the course of their work to provide them with useful information on site, to suggest possible repairs, and to point out potential problem areas [22]. The first attempts to implement AR into maintenance processes date back to the early 1990s. In 2013, Volkswagen introduced a tablet application called MARTA (Mobile Augmented Reality Technical Assistance), which provided technicians with detailed instructions on car repair and maintenance [23]. At present, repair and maintenance technicians are beginning to use AR headsets and goggles in the course of their work to provide them with useful information on site, to suggest possible repairs, and to point out potential problem areas [24].

According to Kelley [26], we know of five ways in which augmented reality will improve industry:

- simplified installation instructions,

- increasing employee productivity,

- effective maintenance of equipment,

- reduction of operating costs,

- quality assurance.

If we want to implement AR in a way that is truly effective and transformative, we need to focus more broadly on the real basic business needs, what further business changes we can make (in the short, medium, and long term), and how AR solutions can overlap with all these changes. To provide an effective and reliable contribution to the transformation of society to achieve goals [25]. In the coming years, we will see manufacturing transformation as companies adopt augmented reality applications as a day-to-day tool for gathering real-time operational reports, improving maintenance and service, 3D design, reducing staffing costs, and developing powerful platforms for remote collaboration without the need for teams nearby.

\section{Materials and Methods}

This section describes the activities performed in order to analyse the current state of use of augmented reality in TPM in industrial enterprises in Slovakia. Using a questionnaire survey, which was designed for medium and large industrial enterprises, we wanted to determine the use of AR in various industries. Data collection took place during the time horizon: 1.4. 2021 - 15.5. 2021. The questionnaire was distributed via Google Form - Questionnaire to 230 industrial enterprises in Slovakia.

The first two questions were focused on the characteristics of industrial enterprises, 1 . the size of the enterprise 2 . the industry in which the enterprise operates. From the questionnaire survey, which was distributed among medium and large industrial enterprises in Slovakia, 135 respondents filled out the questionnaire, the number of employees ranging from 250 to 499 employees. The remaining 95 respondents work in a company with more than 500 employees. 


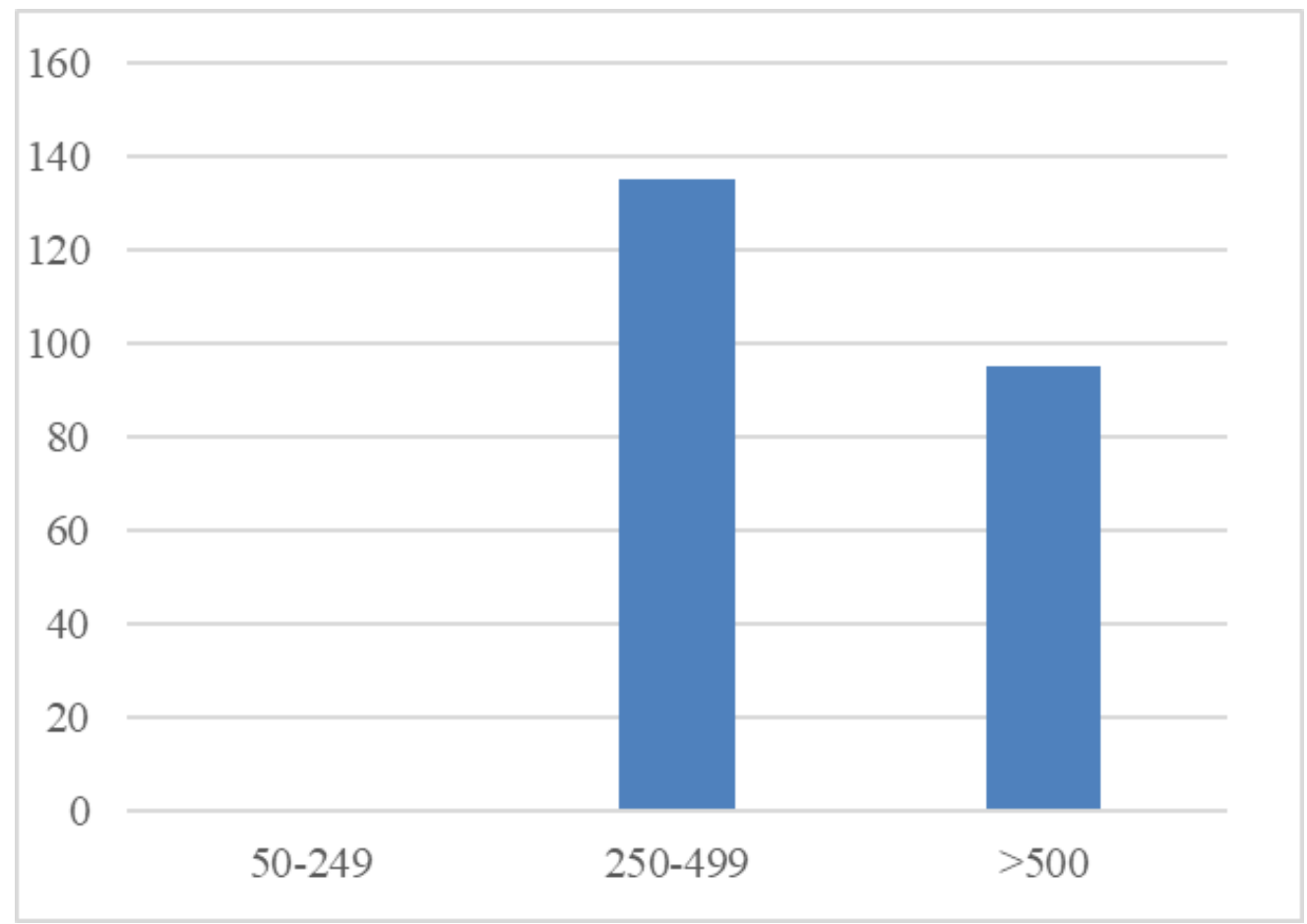

Fig. 2. The number of employees in the company

The second question, "In what industry does your company operate?" was compiled based on the classification of the FinStat site, which was used in creating the database of E-mail contacts. Fig. 3 shows the evaluation of the second question.

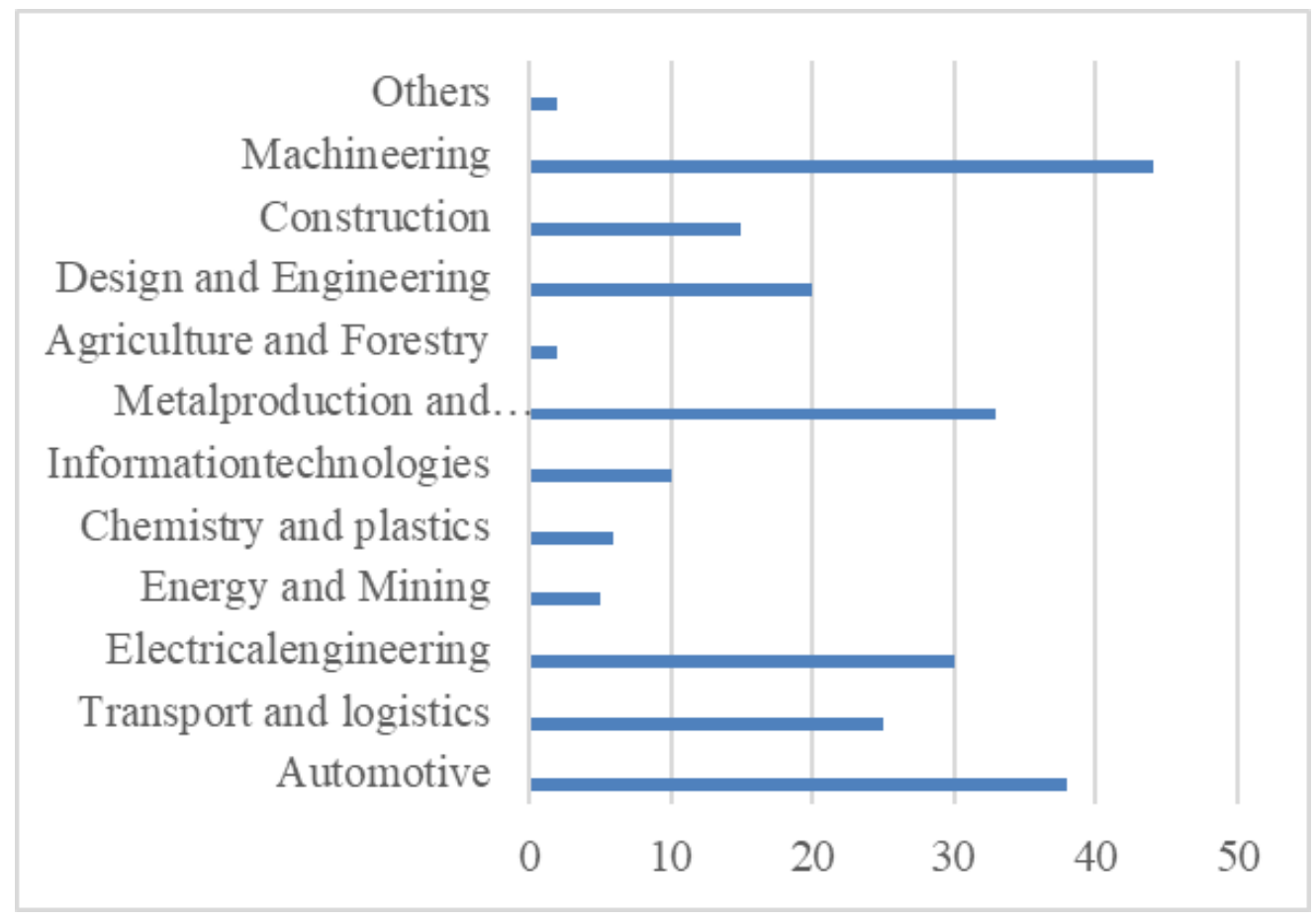

Fig. 3. Industrial sector

Fig. 3 shows that most companies were from the Machineering (44), Automotive (38), Metalworking and Metallurgy (33) sectors. The smallest were industrial enterprises from Agriculture and Forestry (2), Energy and Mining (5), and Chemicals and Plastics (6). The third question of the questionnaire survey focused on the use of AR in industries. "In which industries does AR have the strongest application?" 


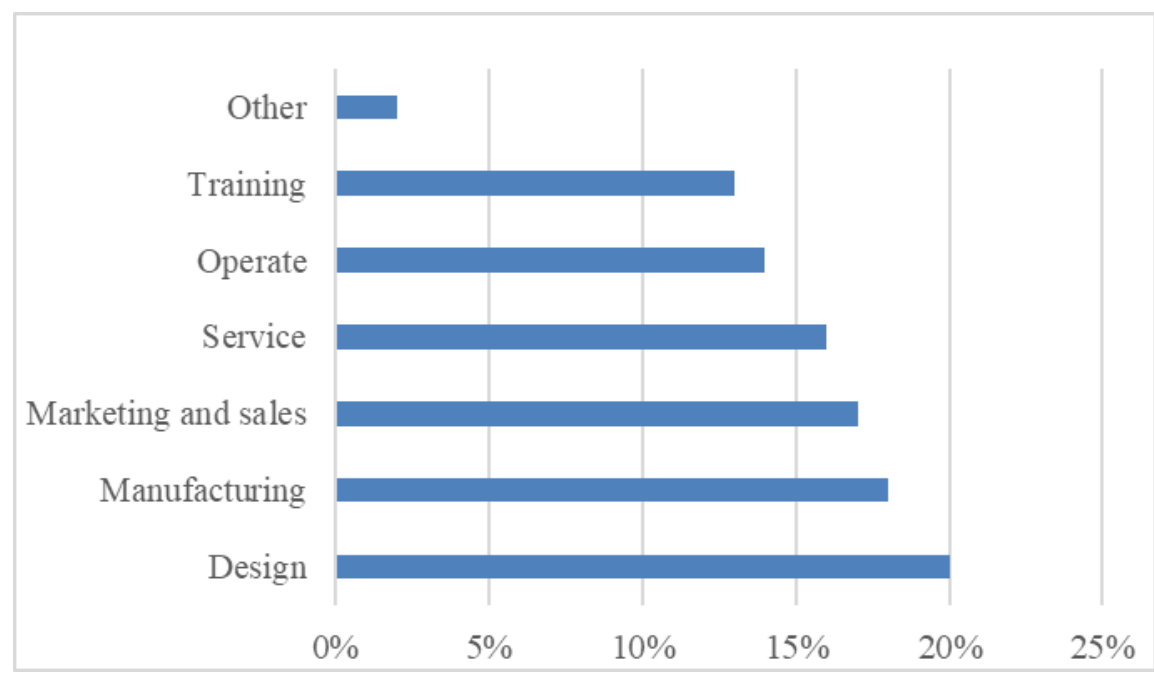

Fig. 4. Representation of AR in Industry

Fig. 4 categorically shows the strongest representation in the design sector (20\%), where AR provides instruments able to improve the prototyping and visualization in the design phase. However, the second is the manufacturing (production) (18\%) the use of which expands reality is the most efficient way and one of the largest industrial cases of AR use. Any operation which provides step-by-step procedures can benefit from the use of AR; installations and assemblies are just a few examples where the AR can make a difference by making the fourth-generation factory. The increased sector consists of marketing and sales (17\%), service (16\%), operate (14\%) and has the weakest representation training $(13 \%)$. In general, the complexity of the technology and the constant need for improvements in terms of time, errors, safety, and costs are the drivers for justifying the utilization of AR. Each field of application seems to have its specific needs and reasons for investing in AR.

\section{Results}

The Results section presents the results of the concept of maintenance support using augmented reality in industrial enterprises in Slovakia. The questionnaire survey involved 230 medium and large industrial enterprises, of which 35\% of companies use AR. Respondents' answers are processed into graphs. The first question from the questionnaire was aimed at identifying the potential of individual characteristic maintenance operations that can be performed by the application of augmented reality by maintenance technicians.

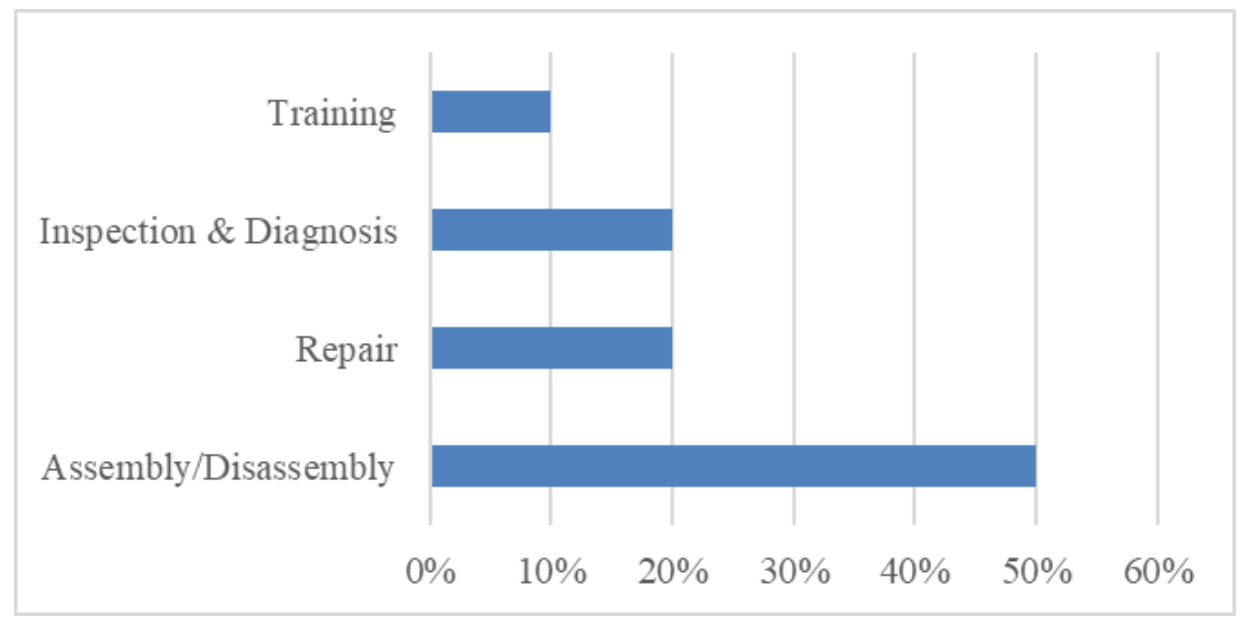

Fig. 5. Maintenance operations

Based on the results of the fig. 5, it is clear that respondents see the greatest potential for the use of AR for maintenance technicians during assembly and disassembly, these operations are the most common operations performed by maintenance technicians. Repairs of equipment and machines and the associated inspection and diagnosis have the same potential (20\%) in the application of AR, based on the respondents. In the training of maintenance technicians, respondents see the least potential $(10 \%)$. 
In the following question, we tried to identify the type of hardware currently used by Slovakia industrial organizations, in connection with augmented reality.

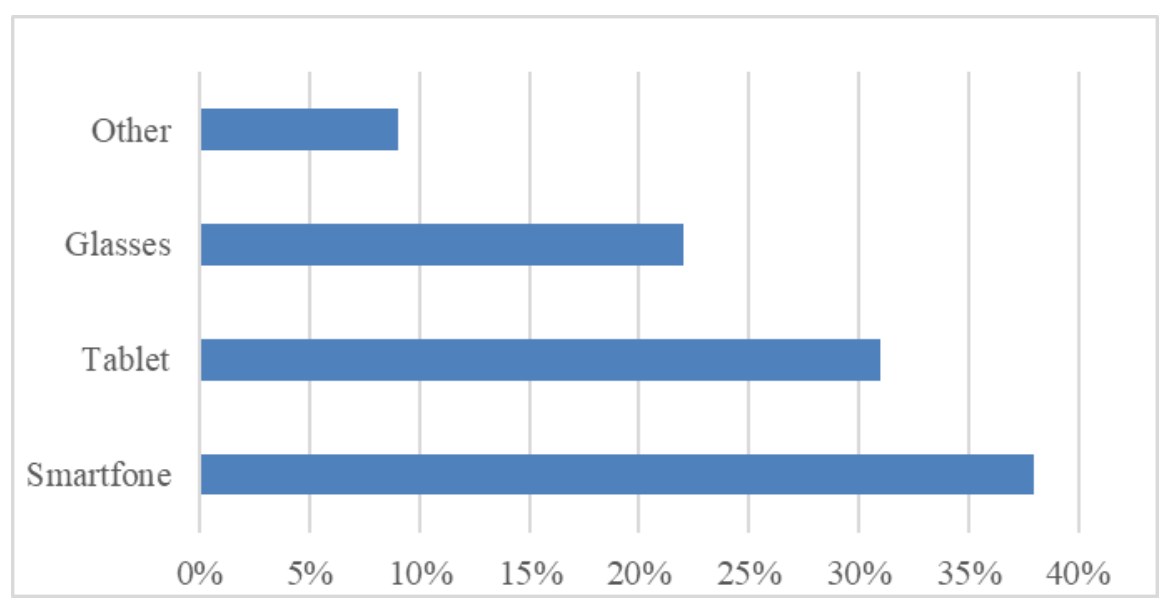

Fig. 6. Use of AR hardware

Based on fig. 6 almost $70 \%$ of respondents use the AR image via smartphones and tablets, which is not surprising given the affordability of these devices. The striking fact is that only $22 \%$ of respondents indicated the possibility of using smart glasses, which expand the abilities and skills of operators, adjusters, installers, maintenance workers, or even quality controllers. By using smart glasses compared to smartphones or tablets, the fact is that glasses are more work efficient, they ensure higher quality and safety of their user.

\section{Discussion and conclusion}

Based on the outputs from the materials section, the authors state that currently, the representation of AR in the industries is the strongest in the field of Design. However, this reality is probably only temporary, due to the COVID-19 pandemic, industry organizations have been forced to increase their investment towards digitization. When comparing the current representation in the sectors fig. 4 and increasing investment in the sectors fig. 7 it is highly likely that the use of AR technologies in manufacturing will be the largest in the future.

Certain research limitations can be attributed to the ongoing COVID-19 pandemic, which has changed the way employees carry out their work activities. The authors of the article assume that a certain part of the respondents to the questionnaire survey did not have to have up-to-date information on the state of implementation of selected Industry 4.0 technologies as a result of working from home. Another limitation can be a result of the individual approach of organizations to the implementation of augmented reality due to the different ways of production of finished goods, their complexity, and strategic visions for the future.

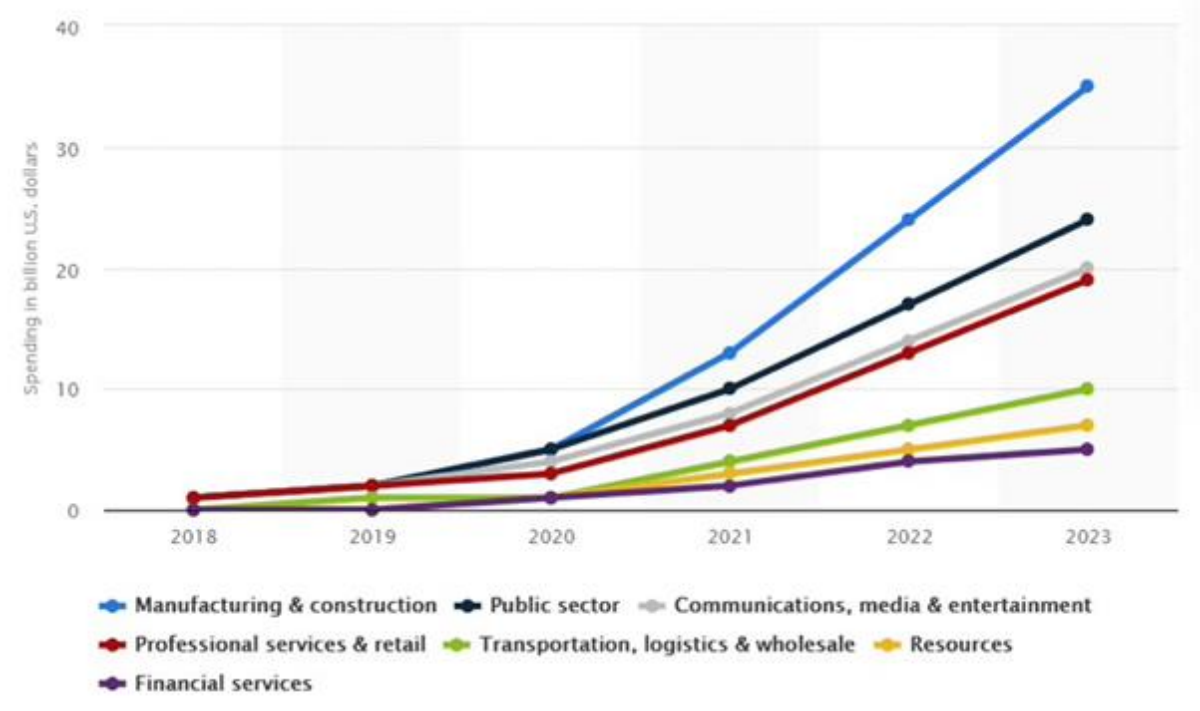

Fig. 7. Expected growth of AR market after considering the pandemic effect. [26] 
Innovations in augmented reality technologies, which have enabled wider implementation in the field of production, have come in recent years and we can assume that their progress will continue in the near future. The size of the global AR market in 2021 is estimated at approximately \$26.75 billion. The expected increase from 2021 to 2028 with a compound annual growth rate could reach up to $43.8 \%$ per year, and in 2028 the size of the AR market could be as high as 360.16 billion [24]. The authors think that a higher share of AR in manufacturing would come regardless of the pandemic, but it has accelerated this process as the priority of digitization of organizations has increased.

Based on the answers of the respondents, fig. 5, the authors found that respondents see the greatest potential in the connection of AR and maintenance of the organization during the assembly and disassembly of equipment and machines. Implementing assembly and disassembly processes using AR technology has many advantages. Workflows that are part of AR technology ensure accurate process progress, which can increase assembly/disassembly productivity, reduce errors, increase product quality, improve ergonomics, and eliminate unnecessary paper documentation and thus ensure environmental benefits. However, this does not mean that the potential that comes with the augmented reality is negligible in inspections and diagnostics or repairs and training of employees.

During repairs, it is possible with AR to use remote cooperation through communication between the technician and the engineer in the field, the engineer can navigate the technician to eliminate the error without his immediate knowledge of the problem. Inspection and diagnostics with AR technology ensure compliance with standardized procedures, thus eliminating the possibility of errors caused by human factors. In conjunction with RFID, QR technology, it is possible to unambiguously identify the inspected parts of the equipment and optimize the inspection process. The inspection record is automatically digitally recorded, so there is no need to create paper records of inspections and diagnostics.

Another category that can be made more efficient by using AR is Employee Training. Training and coaching of employees using AR can streamline the entire process of hiring new employees. AR during training shortens training time, increases its effectiveness, improves quality control during training, prevents errors and at the same time, it is possible to identify potential waste in processes.

Based on the answers of the respondent's fig. 6 to the question of what hardware they use in connection with AR technology in Slovakia, it is clear that most companies currently use tablets and smartphones (69\%). AR glasses, which are becoming more available in Slovakia, are not so much used yet, and are used by only $22 \%$ of respondents. The authors of the article predict that in the future Slovak organizations will adopt more AR technologies in conjunction with AR glasses. AR glasses have many advantages over smartphones and tablets. Users are able to follow instructions without looking at a smartphone, tablet. They can use both hands at work and are not limited by holding the device. A voicecontrolled system and speakers that contain AR glasses are one of the advantages offered by such glasses as they allow control of an AR device without direct contact with the device. Through the implementation of AR technology into maintenance processes, organizations can streamline processes, ensure higher quality and reduce costs associated with maintenance processes. AR technologies offer additional opportunities in improving the philosophy of lean and TPM.

Future research will lead to a more detailed understanding of the potential and possibilities that augmented reality could bring not only as support for TPM but as a change in the perception of current reality in manufacturing and other components of industrial organizations. The aim is to expand knowledge about the ongoing revolution and lay the foundations for further development in the future in terms of technology and their contribution to increasing the competitiveness of organizations in Slovakia. Slovakia is a small country but with the right resources and vision, it could become a powerhouse for industrial organizations across the world.

\section{Acknowledgments}

The authors would like to thank for providing financial support. The paper is a part of project VEGA No. 1/0721/20 „Identification of priorities for sustainable human resources management with respect to disadvantaged employees in the context of Industry 4.0 “.

\section{References}

[1] Segovia D., Mendoza, M., Mendoza E., González, E. (2015). Augmented Reality as a Tool for Production and Quality Monitoring. Procedia Computer Science. Volume 75. Pages 291-300

[2] Bhadury, B. (2000). Management of productivity through TPM. Productivity Vol.41 No. 2 pp. $240-51$.

[3] Wireman, T. (2004). Total productive maintenance. Industrial press, Inc, 200 Madison Evenue, New York, 2 nd ed. ISBN 0-8311-3172-1

[4] Macinnes, R., L., (2006). Štíhlý podnik Memory Jogger: vytvářejte hodnotu a eliminujte ztráty v celém vašem podniku. Praha: Česká společnost pro jakost. ISBN 80-02- 01849-4

[5] Kitain, L. (2018) Industry 4.0 Brings Total Productive Maintenance into the Digital Age. https://medium.com/@lior.kitain/industry-4-0-brings-total-productive-maintenance-into-the-digital-agead050dcb1c87

[6] Ahuja, I.P.S. and Khamba, J.S. (2008). Total productive maintenance: literature review and directions- International Journal of Quality \& Reliability Management, Vol. 25 No. 7, pp. 709-756

[7] Ireland, F. and Dale, B.G. (2001). A study of total productive maintenance implementation. Journal of Quality in Maintenance Engineering, Vol. 7 No. 3, pp. 183-91. 
[8] Diáz-Reza, J.R., Garciá-Acaraz, J.L., Martínez-Loya, V. (2019). Impact Analysis of Total Productive Maintenance. In. Springer Nature Singapore Pte Ltd., 346s. ISBN 978-3-030-01725-5

[9] Augustiady, T.K., Cudney E.A. (2016). Total Productive Maintenance - Strategies and Implementation Guide. CRC Press NW, 292s. ISBN 978-1-4822-5538-6.

[10] Parikh, Y., Mahamuni P. (2015). Total Productive Maintenance: Need \& Framework. International Journal of Innovative Research in Advanced Engineering (IJIRAE) Issue 2, Volume 2, ISSN: 2349-2163

[11] Wakjira, W. M., Singh P. A., (2012). Total Productive Maintenance: A Case Study in Manufacturing Industry. Global journal of researches in engineering industrial engineering. Vol. 12, Version 1.0, ISSN: 2249-4596

[12] Brunskill A., Willmott, P., Quirke J., (2019). TPM - a foundation of operational excellence. Published by SA Partners. ISBN 978-9993748-1-5.

[13] Zlatić, M. (2019). TPM - Total productive maintenance. Quality Festival. ISSN2620-2832

[14] Schwald, B., Laval, B., Sa, T., Guynemer, R., (2003). An Augmented Reality System for Training and Assistance to Maintenance in the Industrial Context. J. WSCG 2003, 11, 1-3.

[15] Ustundag, A., Cevikcan, E., (2018). Industry 4.0: Managing The Digital Transformation. Springer Nature Singapore Pte Ltd., 285s. ISBN 978-3-319-57870-5.

[16] Pabbathi, K.,K. (2018). Quick Start Guide to Industry 4.0: One-stop reference guide for Industry 4.0. Createspace Independent Publishing Platform, 204 pages. ISBN 978-1718978614

[17] Mayr, A., Weigelt, M., Kühl, A., Grimm, S., Erill, A., Potzel, M., Franke, J., (2018). Lean 4.0 - A conceptual conjunction of lean management and Industry 4.0. 72, pp. 622-628, ISSN 2212-8271.

[18] Masood, T., Egger, J., (2019). Augmented reality in support of Industry 4.0-Implementation challenges and success factors, Robotics and Computer-Integrated Manufacturing. 58, pp.181-195, ISSN 0736-5845.

[19] Halenár, I., Juhásová, B., Juhás M., (2018). Rozšírená realita ako nástroj výučby priemyselnej automatizácie. Available from: https://www.atpjournal.sk/novetrendy/rozsirena-realita-akonastrojvyucby-priemyselnejautomatizacie-1.html?page_id=27134.

[20] Azuma, R., Baillot, Y., Behringer, R., Feiner, S., Julier, S., Maclntyre, B., (2001). "Recent advances in augmented reality", 21, pp. 34-47, ISSN 1558-1756.

[21] Williams, D., (2017). The History of Augmented Reality (Infographic). Available from: https://www.huffingtonpost.com/dennis-williams-ii/the-history-of-augmented-_b_9955048.html.

[22] Paine, J., (2017). 10 Real Use Cases for Augmented Realit).Available from: https://www.inc.com/james-paine/10real-use-cases-for-augmented-reality.html.

[23] Grand view research, (2021). Augmented Reality Market Size, Share \& Trends Analysis Report By Component, By Display (HMD \& Smart Glass, HUD, Handheld Devices), By Application, By Region, And Segment Forecasts, 2021 - 2028. Available from: https://www.grandviewresearch.com/industry-analysis/augmented-reality-market.

[24] Wheelwirght, G., (2019). The key role of Augmented Reality in Industry 4.0 for Manufacturing: Part 1. Available from: https://iiot-world.com/industrial-iot/connected-industry/the-key-role-of-augmented-reality-in-industry-4-0for-manufacturing-part-1/.

[25] Saracco, R., (2020). AR Market Gets a Boost from Pandemic. Available from: https://cmte.ieee.org/futuredirections/2020/07/19/ar-market-gets-a-boost-from-pandemic/

[26] Kelley, M., (2019). Five Ways AR Apps Will Enhance Industrial Work in Next Five Years. Available from: https://www.industryweek.com/technology- and-iiot/article/22027338/five-ways-ar-apps-will-enhance-industrialwork-in-next-five-years. 